\title{
Large double Tetrahedral and Prismic bladder stones: A unique Vesicolithotomy findings in a paraplegic:
}

\author{
${ }^{1}$ Mukoro Duke George. B.sc, MB.Bs,DTM\&H Liverpool. \\ ${ }^{2}$ Ikobho D. A.MBBS,FWACS \\ ${ }^{I}$ Department of Emergency Medicine and Traumatology, Niger-Delta University Teaching Hospital. Okolobiri, \\ Yenagoa, Bayelsa, Nigeria. \\ ${ }^{2}$ Department of Surgery, Urology Unit, Niger-Delta University Teaching Hospital, Bayelsa ,Nigeria.
}

\begin{abstract}
:
Introduction: Urinary tract stone is a common phenomenon following severe recurrent dehydration and stasis of urine. They usually form in various shapes and sizes. The reported case was a very unique in shape and size and was formed by the interplay of various precipitating factors including loss of urinary bladder control following spinal injury.

Method: Review of indexed case, the management, radiographic film as well as review of published literatures. Result: The index case was 45 year old paraplegic, who presented with urinary retention, supra-pubic and right iliac fossa pain. Past history of repeated fasting from water. He had emergency $x$-ray of the pelvis which showed two large super-imposed oval shaped homogenous opacities of calcific densities in the pelvic cavity measuring approximately $42 x 50 \mathrm{~mm} \& 39 \times 48 \mathrm{~mm}$. He had a repeat cystolithotomy under general anesthesia. First episode was performed five years ago. The excised stones were uniquely tetrahedron prism in shape. The dry weight of one of them was $46 \mathrm{~g}$ with range of 4.3 to $4.5 \mathrm{~cm}$ in dimensions, while the other was $42 \mathrm{~g}$ with 4.2 to 4.3 centimeters in dimensions. The combine weight of calcium containing stones narrowly escape the criteria of a massive stone, but their shape remains unique.

Conclusion: The stress of surgery and anesthesia can be averted when preventive measures toward stone formation are been practiced.

Keywords: urinary stones, tetrahedron prisms in shape, paraplegic, calcium, cystolithotomy.

\section{Introduction:}

Urolithiasis is caused by multiple factors. Urolithiasis encompasses both renal, vesical, ureteric stones. Stone disease varies with age, gender, ethnicity and season ${ }^{1}$.Fifty percent of patients will have recurrent stone disease within 5 years, so it can be considered a disease for life ${ }^{2}$.Natural history of stone formation involve super saturation of urine with salt such as calcium compounds which begin to aggregate overtime, when inhibitory factors are defective, the formation progresses. This article attempts to introduce the complex etiology of stone shape in the index patient, highlight the natural history of stone disease when left untreated and cover important points of contemporary management.
\end{abstract}

\section{Method}

The folder containing necessary information of the patient was retrieved and after consent was obtained from the patient to use information for research purposes only, full name of patient was not used in keeping with confidentiality.

\section{Case presentation}

MR GM was a 35 year old paraplegic with occasional incontinence of eleven years duration following a road traffic accident. He presented with 6 hours history of urinary retention with associated supra-pubic and right iliac fossa pain of 16 hours duration. He had open reduction -internal fixation for the right femoral fracture 11 years ago at a tertiary centre and cystolithotomy for Intra-vesical calculi(vesicoliths), five years ago with a confirmatory post-operative x-ray film. Prior to his recent presentation he has past history of urinary incontinence following loss of bladder control after the road traffic accident and usually embarks on fast from taking water. He had attained some bladder control before presentation through self training; however, there was no history of fecal continence or symptoms suggestive of prostate enlargement. On examination, vitals signs were 88 beat per minute, 130/90mmhg.First and second heart beats were heard. There was supra pubic fullness with infra-umbilical incisional scar. He had a temporally, Foley's catheter in-situ. There was marked reduction in the tone of his lower limbs and absence of power. An emergency x-ray of the pelvis was done which showed two large super-imposed homogenous opacities of calcific densities in the pelvic cavity measuring 
approximately $42 \times 50 \mathrm{~mm} \& 39 \times 48 \mathrm{~mm}^{\text {Figure } 1}$. Osteophytic lippings were on both ishial tuberiosity \& ischiopubic junctions. Soft tissue and capsular calcifications were seen over both hip joints.

Figure 1:Xray-film showing Stones in Urinary Bladder with ORIF plate at Right hip.

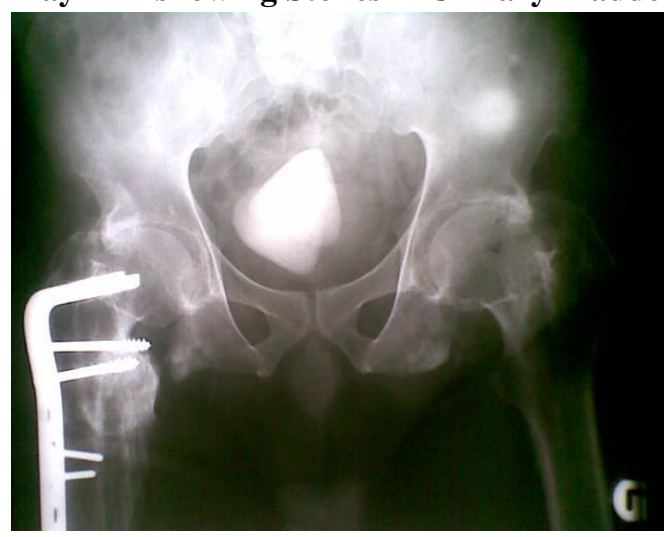

Both hip joint spaces are asymmetrically narrowed. There is a plate and screws on the right femur with sclerosis and widening of the lesser trochanter. The right infra-trochanteric soft tissue showed calcification. He was diagnosed as a case of recurrent vesiculolithiasis secondary to neurogenic bladder dysfunction from spinal cord injury with bilateral Hip osteoarthrosis. Laboratory serum investigation showed pack cell volume of $42 \%$, normal white blood cell differential count as well as serum electrolyte levels. Mild hyperuriceamia of $7.2 \mathrm{mg} / \mathrm{dl}$ was seen. Urine microscopy and culture showed numerous pus cells, mild proteinuria, moderate microscopic hematuria and bacteriuria. An emergency cystolithotomy under general anesthesia was done.

Figure 2: Freash (wet) excised tetrahedral Prismic stones

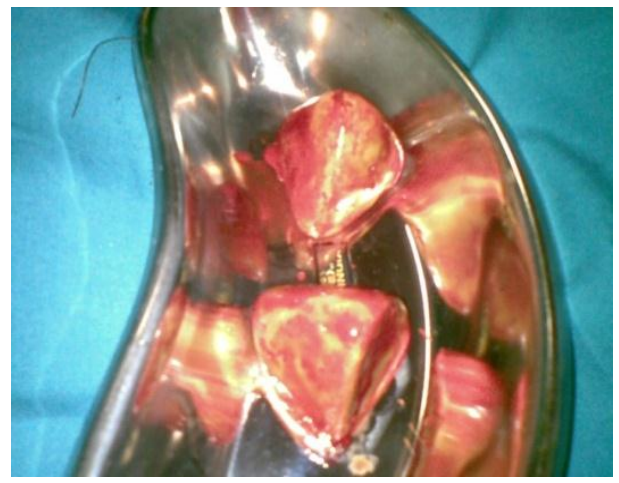

Post operative period was uneventful. Surgical findings included stones secured to the wall of the urinary bladder by multiple adhesions. After excision, the wet sizes of both stones were $6 \mathrm{~cm}$ by $4 \mathrm{~cm}$ by $6 \mathrm{~cm}$ in dimension. Figure 2

figure 3: dry stones with measurement line

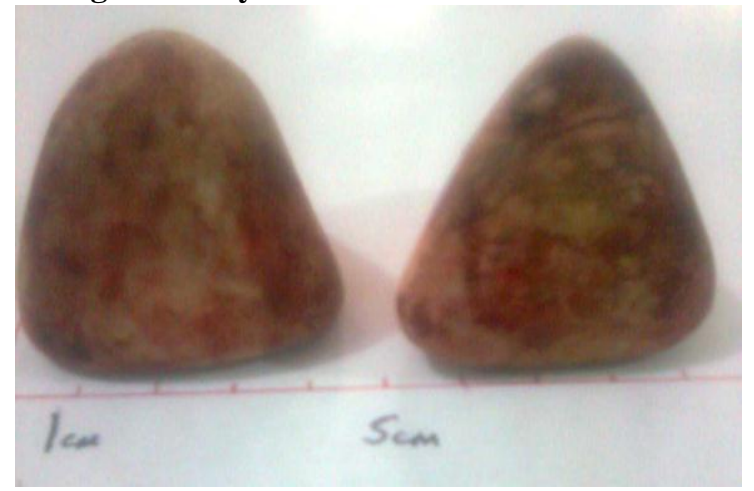

However, dry weight of one of them was $46 \mathrm{~g}$, and 4.3 to $4.5 \mathrm{~cm}$ in dimension, while the other was $42 \mathrm{~g}$ with dimension of 4.2 to 4.3 centimeters .He was administered antibiotics (Ofloxacin, Genticin, and Metronidazole), analgesics (Melocap and pentazocine) and Hematinics (Fesolate, vitamin c and Folic acid).He was managed within 9 days and discharged home for follow-up in urology clinic. 


\section{Discussion:}

The super-saturation of the urine ${ }^{3}$ results in formation of the nucleus and crystallization of constituents leading to stone formation. The process is usually potentiated further by stasis and recurrent infections. Other factors that precipitate stone formation include partial ureteric duplication ${ }^{4}$, spinal injury with loss of bladder function and dehydration as seen in our case.

The urine normally contain compounds that inhibit stone formation, if absent or defective, lead to stone formation. Calculi are of different constituents including calcium, oxalate, uric acid, magnesium, phosphate, ammonium and cystine. Eight five percent of stones are calcium-based stones such as calcium oxalate and calcium phosphate. Ten to fifteen percent are infection or struvite calculi, approximately 5\% to $10 \%$ are uric acid calculi, and rarely cystine calculi. Over $90 \%$ of calculi are radio-opaque, and only uric acid, indinavir calculi are truly radio-lucent ${ }^{5}$.The reported case from x-ray film showed that it contain good concentration of calcium salt, therefore it was radio-opaque.

Untreated stones vary in size and location. Staghorn or partial stag-horn stones are common pylonephron in site formation. Ureter and kidney stones are smaller compared to bladder stones and usually cause early symptoms with changes in renal blood flow. The passage of stone depends on size, location, and side ${ }^{6}$. Stones that are $4 \mathrm{~mm}$ or less have a $90 \%$ chance of passing independent of surgical intervention.

Diagnosis of urolithiasis depend on previous episodes of stone disease and family history of stone disease ,diet (high salt and oxalate),inadequate fluid consumption, medications, disease processes (such as gout,diabetes, bariatric surgeries, inflammatory bowel disease), immobilization, urinary/bowel diversion surgery .

Investigations that support diagnosis include, CT scanning without contrast which is the most accurate imaging available. However it is expensive and not readily accessible in some areas. Alternatively an ultrasound scan with Kidney Ureter Bladder (KUB) and X-Ray may be considered ${ }^{7}$ as shown by the reported case. Patients with obstructed and infected system, obstructed solitary kidney, bilateral obstructions, renal impairment or failure, acute and chronic urinary retention from vesicolithiasis and those in whom adequate analgesia does not control their pain requires urgent surgical intervention.

Smaller stones are partially amenable to dissolution therapy using medication such as such as potassium citrate; these include uric acid and cystine stones ${ }^{5}$. Stones greater than or equal to $5 \mathrm{~mm}$ has decreased likelihood of passing spontaneously and hence to prevent a long term sequelae should be managed surgically ${ }^{9}$.Minilaparoscopic operations has its limit in term of size of the stone that can be removed by the procedure only. Therefore it is advisable to remove bladder stones getting to $5 \mathrm{~cm}$ through open surgery ${ }^{9,11}$. Ureteric stones $4 \mathrm{~mm}$ or less can be considered for medical expulsion therapy (MET) ${ }^{8}$ using Alpha blockers and Calcium channel blockers.

Extra Corporeal Shockwave Lithotripsy (ESWL) should be considered for smaller symptomatic renal stones. The most likely site for very large stone is the urinary bladder due to its voluminous cavity, and researchers have been trying to report various sizes such as $8.0 \times 10.0 \times 5.0 \mathrm{~cm}$ by Gürdal et al ${ }^{10}$ and $12.0 \times 9.5 \mathrm{x}$ $7.0 \mathrm{~cm}$, weighing $810 \mathrm{~g}$ by Sung-Lang Chen et al. ${ }^{11}$ A weight of $100 \mathrm{gm}^{11}$ is termed giant, while for the index patient the combined weight was $88 \mathrm{~g}$. Fortunately commonly reported shapes from the bladder are roughly spherical ones and that from the index patient was uniquely tetrahedral and paired.

The very large ones were often removed through surgical techniques however surgeons are begin to apply the shock wave technique, but which size and weight is the maximum limit for this new technique is yet to be established.

\section{Conclusion:}

Urolithiasis should be prevented as much as possible, however when seen in patients, they may present in various shape and sizes, therefore, surgeons should equip themselves with necessary skills and apply best methodology available to removes these stones based on their sizes from the urinary tract thereby preventing possible morbidity. Open surgery is still a viable option for very large bladder stones.

Conflict of interest: none to declare.

\section{References:}

[1] Lo S, Johnston R, Al Sameraaii A et al. Seasonal Variation in the Acute Presenta-tion of urinary Calculi over 8 years in Auck-land, New Zealand.Brit J Urol Internat. 2009; 106: 96- 101.

[2] Trinchieri A, Ostini F, Nespoli R et al. A pro-spective study of recurrence rate and risk factors for recurrence after a first renal stone. J Urol. 1999; 162: 27-30.

[3] Coe FL, Evan A, Worcester E. Kidney stone disease. J Clin Invest. 2005; 115(10): 2598-608.

[4] Eroglu M, Unsal A, Cimentepe E, Bakirtas H. Giant ureteral stone associated with partial ureteral duplication. Int Urol Nephrol. 2003;35(4):485-7.Turkey.

[5] Lawrence A, Koya MP.Management of urolithiasis - a review,Samoa medical Journal pP41-43. 
[6] Ueno A, Kawamura T, Ogawa A, Takayasu H. Relation of spontaneous passage of ureteral calculi to size. Urol. 1977; 10(6): 544 546.

[7] Niemann T, Kollmann T, Bongartz G. Diagnostic Performance of Low-Dose CT for the Detection of Urolithiasis: A Meta-Analysis. American journal of Roentgenology.2008; 191:396- 401.

[8] Seitz C, Liatsikos E, Porpiglia F, Tiselius HG, Zwergel U. Medical therapy to facilitate the passage of stones: what is the evidence? European Urology. 2009; 56(3):455-71.

[9] Fabio Cesar Miranda Torricelli' Eduardo Mazzucchi' Alexandre Danilovic Rafael Ferreira Coelho' Miguel Srougi, Tcbc-Sp' Surgical management of bladder stones: literature review: Rev. Col. Bras. Cir. vol.40 no.3 Rio de Janeiro May/June 2013.

[10] Gürdal M, Ayyildiz A, Huri E, Kanberoğlu H, Karaman MI. A huge bladder cystine stone, Int Urol Nephrol. 2003;35(4):497-9.

[11] Sung-Lang Chen, Yu-Lin Kao, Siu-San Tse; A Giant Bladder Stone Managed with Obstetrical Delivery Forceps. JTUA, 14:201-204, 2003 